\title{
PESQUISAR PARA ASSISTIR
}

Edna Apparecida Moura Arcuri*

Evocando os recónditos de minha memória, tentando identificar as raízes do início de minha formação como pesquisadora, deparo-me com os acontecimentos da década de 60 , quando, recém-graduada, atuava como docente assistencial na área de saúde pública. Não foram necessários muitos meses para perceber que as ações de enfermagem deveriam transcender os clássicos conselhos dirigidos à família, direcionados para a necessidade do exame médico periódico, freqüência ao centro de saúde, valor nutritivo dos alimentos, importância das vacinas, etc. A despeito dos momentos gratificantes que ocorriam na demonstração do primeiro banho do bebe à mãe primigesta, e outros, minha atenção começou a voltar-se para as situações difíceis e frustrantes, com ações inóquas diante dos clientes não aderentes ao tratamento, às vezes agressivos, sobretudo pessoas diabéticas, hansenianas e tuberculosas.

Em 1965 freqüentei o primeiro curso de "Iniciação d Pesquisa ", porém o 1- projeto de pesquisa, voltado para a busca da melhor compreensão da resistência do diabético (na época não se usava o termo aderência), nunca foi finalizado.

Os fatos que originaram a crença "é necessário pesquisar para melhor assistir " tiveram início na década de 70, quando cursei Mestrado. A dissertação intitulada "Estudo das condiçðes bacteriologicas da unidade do paciente momentos antes de sua internação " recebeu um Prêmio da Federaçao Brasileira de Hospitais devido à importância que começou a ter o problema das infecções hospitalares. Mas o fato mais importante, para mim, foi verificar que entre os vários elementos examinados (roupas de cama, travesseiros, mesa de cabeceira, etc), o menos contaminado era a cadeira. S 6 então passei a dizer aos meus alunos que eles poderiam sentar-se para conversar com seus pacientes, posicionando-se à altura de seus olhos, na busca de uma interação mais efetiva, pois a cadeira " não era o local mais contaminado"; por esta razão náo foi permitido que sentássemos nas enfermarias durante todo o nosso curso de graduaçăo, pois "nosso uniforme levaria contaminação para outros locais".

Foi uma pergunta feita constantemente por alunas do curso de graduação, entretanto, que direcionou a trajetória da investigação em minha vida académica. Durante as aulas práticas da mensuração da pressão arterial, deparava-me constantemente com uma questão para a qual não tinha resposta convincente: "sou

- Enfermeira. Professor Titular do Departamento de Enfermagem Médico-Cirúrgica da Escola de Enfermagem da USP. 
hipotensa?"... " minha pressão é dez por seis"... "nove por cinco"...etc. De fato, naquela época era preocupante o número de mulheres jovens que se julgavam hipotensas e consumiam drogas vasoconstrictoras, particularmente nos dias quentes de verão. Como o aluno poderia considerar a própria pressão dentro dos limites da normalidade, se a realidade das aulas práticas de fisiologia levava-o a acreditar que a pressão média era por volta dos $100 \mathrm{mmHg}$, como era referida no Compêndio de Fisiologia do Guyton?

$\mathrm{Na}$ tentativa de melhor compreender ou explicar o problema comecei a procurar especialistas da área de nefrologia e cardiologia; contudo, não encontrei respostas consistentes e muitos afirmavam que as mulheres tinham a mania de ser hipotensas: "a mulher tem cefaléia e a culpa é da pressão"... " tem cólica ou briga com o namorado, sente-se mal e pensa que a pressão é que está baixa"... " tem..." e assim fui colecionando um repertório de frases sobre a falsa pressão baixa das mulheres.

O livro "High biood pressure ", de Sir George Pickering, foi o ponto de partida para meu conhecimento dos principais periódicos na área, mas foi no "American Journal of Nursing" onde me deparei pela primeira vez com uma informação comumente encontrada na literatura, a qual recomendava que a largura do manguito do esfigmomanômetro fosse proporcional ao diâmetro do braço, a fim de evitar hiper ou hipoestimação dos valores intrarteriais. Toda a preocupação identificada na literatura e na área assistencial, entretanto, dizia respeito à hiperestimação da pressão arterial em pessoas obesas, podendo levar ao falso diagnóstico da hipertensão.

A possibilidade do fenômeno contrário ocorrer, ou seja, hipoestimação por tamanho inadequado do manguito, conduzindo ao auto-diagnóstico de hipotensão, levou-me a testar, em 1.000 pessoas, $a$ influência da largura do manguito na medida da pressão arterial. O protocolo de pesquisa foi delineado com base na informação que o manguito de largura correta deveria ser igual a 0,38 da medida da circunferência do braço ( $20 \%$ maior do que o seu diâmetro). Um conjunto de manguitos, variando a cada centímetro (de 8 a $14 \mathrm{~cm}$ ), permitiu a escolha do manguito próprio para cada braço e a comparação do registro realizado com o manguito de largura padrão, com um minuto de intervalo entre as medidas. Os créditos realizados durante o curso de Fisiologia foran dirigidos para a compreensão de um protocolo que conseguisse controlar ao máximo as diversas variáveis associadas à pressão arterial, relacionadas aos erros causados pelo instrumento, cliente ou observador, sobretudo o controle do alerta.

São apresentados a seguir algumas conclusões das nossas atividades de pesquisa realizadas de 1980 até os dias atuais, abordadas em extensão nas teses de doutorado e livre docência e em algumas publicações, atividades estas realizadas com a colaboração dos assessores na parte de hemodinâmica e estatística e 2 alunos monitores do laboratório de esfigmomanometria e hipertensão do Departamento de Enfermagem Médico-Cirúrgica.

1. As médias finais de pressão arterial obtidas com o manguito de largura correta em 1.000 pessoas, no primeiro estudo, foram de $121,9 \mathrm{mmHg}$ para a sistolica e $80,2 \mathrm{mmHg}$ para a diastólica. Essas médias, semelhantes às admitidas internacionalmente para os adultos em repouso, validam a informação de que a largura do manguito deve ser $20 \%$ maior do que o diàmetro do braço $(0,38$ da circunferên- 
cia), para evitar hiper ou hipoestimação dos valores registrados, comparativamente aos intrarteriais. Evidentemente, o rigor metodologico que adotamos no sentido de controlar as demais variáveis implicadas, foi fator crucial para a obtenção dessas médias.

2. A comparaçã́c dos resultados da aplicação do índice de Quetelet à nossa população com os resultados para outras, assim como a comparação da circunferência de braços de bäasileiros e italianos, permite-nos concluir que esse parâmetro dos brasileiros é semelhante aos padröes de grande parte das populações mundiais, sobretudo ocidentais.

3. O uso do manguito de largura padrão pode provocar hiperestimação doss valores da pressão arterial em obesos, fato bastante difundido na literatura. Contudo, a preocupação deve estar igualmente voltada para as pessoas com peso normal e principalmente as magras, as quais têm sido erroneamente discriminadas, tendo em vista o risco a que estão expostas, conforme evidenciou a evolução da pressão nos participantes de nosso estudo relatada neste trabalho.

4. Os valores da pressão arterial não sofreram alterações em função da ordem em que empregamos os manguitos de largura correta ou de largura padrðo, uma vez que as medidas obtidas com um e com outro mantiveram-se as mesmas, independentes da ordem de utilizaçáo. Esse fato demonstra que não há um fator temporal, que poderia estar relacionado com alerta, habituação ou outra variável fisiologica, implicado nas diferenças que verificamos, sendo estas claramente devidas à diferença de largura dos manguitos.

5. Os resultados indicam, tambem, que a utilização de tabelas de correção de erros pode agravar ainda mais o problema, encobrindo o erro decorrente da inadequação do manguito e desviando a atenção dos sintomas importantes. A correção proposta não leva em consideração diferenças individuais importantes, possivelmente relacionadas à espessura da artéria, que já pode estar comprometida por hipertensão, fatores genéticos e potencial para reatividade vascular.

6. Nossos achados oferecem uma explicação plausivel para a maior proporção de mortes por moléstia isquêmica em magros hipertensos. Nesses indivíduos, a hipertensão pode permanecer oculta durante muitos anos por falta de diagnóstico e, mesmo quando finalmente diagnosticada, a doença pode ser insuficientemente tratada porque as doses de hipotensores prescritas são menores que as necessárias. Em contraposição, nos obesos a hipertensão é diagnosticada precocemente e os medicamentos são prescritos em doses maiores do que o necessário, favorecendo a terapêutica e o prognóstico.

7. Os resultados de nossos estudos proporcionam uma explicação consistente para os baixos valores da pressão arterial em mulheres jovens, desmistificando o problema da " hipotensão" feminina e esclarecendo o desnecessário consumo de drogas vasoconstrictoras. Se, como já informamos, 75 entre 450 mulheres $(16,6 \%)$ haviam consumido esse tipo de droga, é preciso ressaltar que apenas 5 entre 450 homens $(1,1 \%)$ haviam necessitado de vasoconstritores para "aumentar a pressão", segundo informaram no estudo anterior.

8. O depoimento apresentado por uma das participantes do estudo evidencia a ocorrência de sérias falhas na avaliação da pressão arterial de gestantes magras, o que aumenta o risco de complicações e até mesmo de vida da mãe e da criança, situação essa que requer urgente investigação.

Os achados resultantes de nossos estudos permitem estabelecermos um 
paralelo e diferenciação condizente à pertinência e ao valor da pesquisa quantitativa e qualitativa. Jamais poderfamos levantar importantes hipóteses na área de hipertensão, como o questionamento sobre o real valor das tabelas de correção de erro provocado pelo manguito padrão, se não tivéssemos estudado um grande número de pessoas. A relevante quantidade de participantes na amostra populacional permitindo uma estratificação em lustros (subgrupos a cada cinco anos) favoreceu a compreensão e melhor análise da curva da pressão na idade e responde à questão inicial, esclarecendo que as mulheres jovens não são hipotensas, pois os baixos valores são resultantes do erro introduzido pelo instrumental inadequado.

O acompanhamento individual de algumas pessoas que consideramos "de risco" nos estudos iniciais, contudo, alcançou resultados semelhantes aos almejados pela abordagem qualitativa, embora desprovidos de um referencial teórico específico. O seguimento de cada uma dessas pessoas dependeu do controle das variáveis inerentes às peculiaridades de cada personalidade. Apresentamos, a seguir, o depoimento já referido, resultado inquestionável de uma abordagem individual da interação efetiva com um dos sujeitos de nossas açóes como pesquisadoras.

\section{Depoimento de uma paciente (N.Y.M.J., docente da USP)}

Tendo em vista minha participação na primeira pesquisa realizada na Universidade de São Paulo pela Dra. Edna Arcuri e também como docente e pesquisadora desta Universidade, estou oferecendo este depoimento, a fim de participar e contribuir para a continuidade dos estlidos, considerada a relevência dos fatos ocorridos.

Em seqüência, estão relatados os fatos que se relacionam com o assunto em pauta:

Na minha segunda gestação (abril de 1983) ocorreu, sem causa aparente, um descolamento precoce de placenta que exigiu uma cirurgia de emergencia, que colocou em perigo tanto a minha vida como a do bebê. Segundo o depoimento do próprio médico obstetra, era um fato inexplicável para mim, em função dos acompanhamentos feitos, o que lhe causou sérios problemas. Um dos comentários foi "Você teve a primeira gestação sem problemas e nem tem problemas de hipertensão... não consigo explicar...".

A partir dessa época vinha tendo constantes dores de cabeça. Toda vez que me queixava de cefaléia vinha a resposta de que provavelmente era decorrente das duas anestesias simultâneas que tive que tomar e que com o tempo viria a melhorar.

A dor persistia e até chegava a ser insuportável. Na consulta a um clínico geral, nada conseguiu-se detectar. Mais tarde comecei a ter problemas de visão, cuja acuidade aumentava e diminuia conforme o dia.

Uma consuita a um oftalmologista nada revelou e o fato da minha cefaléia ser acentuada de manhã fê-lo descartar alguma anomalia visual como causa do problema.

Nessa época, por coincidência, participei das medidas da Dra. Edna. Quando ela se mostrou intrigada e realizava novas medidas, comentei "Não se preocupe que sempre tive pressão baixa". Qual foi a minha surpresa quando 
soube que com o manguito correto era exatamente o contrário. Depois de conversar verificamos que os sintomas que vinha apresentando poderiam ser da hipertensão. A Dra. Edna aconselhou-me a procurar um médico especialista.

Fui novamente ao clínico geral e relatei todos os fatos, inclusive a exposiçáo da Dra. Edna. Ele disse-me que não acreditava muito mas, por via das dúvidas, me encaminharia ao cardiologista. Em agosto de 1984 fez-se um eletrocardiograma que nada detectou e o problema foi deixado de lado. Relatei o fato a Dra. Edna, que, preocupada com o meu caso, telefonava para acompanhar.

Um pouco antes da minha viagem ao Japão para o meu pós-doutoramento (setembro de 1984), consultei novamente um oftalmologista e clínico geral, pois a dor persistia e isso me preocupava muito. Enfim, nada foi detectado e a única solução foi levar comigo um estoque de remédios (Dorflex, principalmente).

Mais uma vez tive problemas, mas agora no Japåo. Lá o oftalmologista constatou que as lentes dos meus óculos estavam com grau incompatível (cerca de um grau mais forte). Fez-se a substituição das lentes e considerei encerrada a procura da causa para a minha cefaléia. Mas esta, mais tarde, tơrnou a voltar.

Logo que retornei ao Brasil, em janeiro de 85, fui consultar novamente meu oftalmologista, o qual constatou que o meu grau correto estava mais baixo e o considerou como um caso interessante para estudo. No entanto, a minha dor de cabeça persistia e aumentava.

A cefaléia chegava a ser insuportável, causando crises como náusea, vômitos e dores insuportáveis que me faziam rolar na cama. No retorno ao clínico geral, este solicitou um raio-X dos seios da face. Os exames feitos em 08/85 e 10/85 acusarain um espessamento polipoide da mucosa do seio maxilar, que foi diagnosticado como decorrente da alergia (rinite alérgica) pelo otorrinolaringologista.

Após o tratamento, foi resolvido que eu seria submetida a cirurgia para a sua remoção, uma vez que a minha dor de cabeça tornava-se cada vez pior e nenhum remédio fazia efeito. No entanto, o médico deixou claro que isto poderia não ser a causa da minha cefaléia. No hospital, constatou-se que a pressão estava extremamente alta e a cirurgia só se realizou após ser contornado esse fato com a administração de medicamentos. Foi recomendado controle e tratamento.

Após dois meses, depois de persistirem os problemas com intensificação das dores, náuseas agora acompanhadas de região occipital dura e palpitaçőes, realizou-se uma consulta com um clínico geral/cardiologista que confirmou a minha hipertensão. Na ocasião, relatei o fato de uma professora da USP já ter detectado o fato havia muito tempo. Ele se interessou pelo assunto e recomendou exames e tratamentos. Disse-me tratar-se de um caso não muito comum de uma hipertensão numa pessoa jovem e magra.

Desde esse período até o momento continuo tomando um comprimido de Viskaldix por dia e a cefaléia desapareceu logo depois de 10 dias. Foi uma coisa incrivel depois de tanto tempo de sofrimentos e de dias pouco produtivos. A única conseqüencia que carrego é a lesão nas retinas, causada pela hipertensão, que estagnou, porém não regrediu (exame confirmado em 10/87). Felizmente não afetou a visão. Os exames realizados como eletrocardiograma e ecocardiograma não detectaram anomalias Eventualmente tenho hemorragias nasais.

São estes os fato. lacionados com a minha saúde e bem estar e, em parte, o depoimento foi feito para que o relato possa auxiliar outras pessoas como eu, cuja detecção da hipertensão foi e é dificultada pelas características físicas. Cabe 
ressaltar que desde que ela foi diagnosticada, poucos acreditaram ou ainda, levami em consideraçăo o relato. Em fevereiro de 1987 fui submetida a uma histerectomia e antes e depois da cirurgia, sempre alertei sobre a minha hipertensáo e o fato de controlá-la com remédio. No entanto, percebi que poucos consideravam isso e senti total descrédito quando muitos comentavam "Imagine, sua pressáo está até um pouco baixa".

\section{assinatura da depoente}

São Paulo, 04 de setembro de 1988

O depoimento apresentado constitui um fator de motivaçăo para enfrentar os desafios impostos pela carreira academica, pela interdisciplinaridade e pela realidade de ser enfermeira neste país. Há ainda o caso de uma ex-aluna da EEUSP, que teve seus rins transplantados poucos anos apos termos levantado, com insistência, a hipotese de se tratar de uma pessoa hipertensa, o que foi totalmente rcjeitado pelos nefrologistas devido aos baixos valores registrados em seus braços finos. Era uma pessoa pequena, magra, com 46 quilos. Outros ex-alunos tem me procurado para confirmar a hipertensáo prevista 10 anos antes. A despeito da descrença de alguns assessores de agencias financiadoras de pesquisa, que tentam empalidecer qualquer tentativa de chamarmos atenção e divulgarmos nossos resultados, contrariamente a postura cientifica e do respeito de outros, é cada vez mais forte a nossa crença de que é preciso pesquisar para assistir. Existe, nos enfermeiros, uma grande potencialidade para conhecerem a fronteira do conhecimento e identificarem os aspectos mais frágeis que necessitam ser investigados, diante do compromisso de ajudar pessoas a manterem ou restaurarem o equilíbrio, no continuum saúde-doença.

Parafraseando Paul White (relacionado a moléstias cardiovasculares), " nenhum pats sozinho conquistara a qualidade da assistencia de enfermagern' 'e ninguém sabe de que fontes novas descobertas emergirão ". A pesquisa é o desafió que deve ser enfrentado para cuidar com competencia do paciente/cliente, e garantir a qualidade da assistencia de enfermagem. 